\title{
Collegiate Neurosurgery in Disaster and Mass Medical Emergencies: Lessons Learned from Mexico
}

\author{
Rodrigo RAMOS-ZUÑIGA ${ }^{1}$, José Rodrigo ARELLANO-CONTRERAS ${ }^{1}$, Jorge Alejandro ROCHIN-MOZQUEDA ${ }^{1}$, \\ José Alberto PLASCENCIA-JIMÉNEZ1
}

\begin{abstract}
University of Guadalajara, Health Sciences University Center, Institute of Traslational Neurosciences, Department of Neurosciences, Guadalajara, Mexico
\end{abstract}

Corresponding author: Rodrigo RAMOS-ZÚÑIGA rodrigorz13@gmail.com

\section{ABSTRACT}

Every year, natural or people-generated disasters disrupt the functioning of society, causing human, and material loses, which lead to an increase in the demand for medical attention. In the morning of September 19, 2017, a 7.1-magnitude earthquake struck Mexico City and four other cities, leaving around 19 million people affected and 331 dead. Although the medical response was timely, most of the efforts fell short because demand exceeded responsiveness. This incident evidenced the challenges that we have as caregivers with mass medical emergency, and the need for direct and well-structured interventions of professional-medical associations in the immediate response, on both in-site and in-hospital settings.

The aim of this paper is to analyze how we respond to these medical emergencies and what new strategies have been proposed in order to identify the weaknesses and areas of improvement, as well as to restructure our methods of emergency intervention. We searched all the information in both official institutional and social media with a public sanitary scope. We submitted this information to a descriptive qualitative analysis and compared with official information and management. We found an important role for social media as a means of communication and civil organization. Collegiate medical societies, such as neurosurgeons, showed a limited reach, little on-site intervention, and poor use of social media and other strategies to improve the response. Finally, we propose how we may approach these mass medical emergencies in a better way, taking advantage of new technologies and strategies.

KEYWORDS: Disaster medicine, Medical emergency, Neurosurgery

ABBREVIATIONS: ATLS: Advance trauma and life support, DigiDOC: Digital disaster operations center, IMSS: Mexican institute of social security, SCEO: State center of emergency operations, STCONARPA: Technical secretary of the national council for the prevention of accidents, USD: United States dollars, CVOED: Virtual Center of operations in emergencies and disasters

\section{INTRODUCTION}

A disaster is a natural or human-generated event that seriously disrupts the functioning of society in a sudden way, causing human, material, and ecosystem losses (Table I). It also creates a significant short-term increase in the demand for emergency services, requiring extraordinary measures to address the situation that tendsto fall short because demand generally exceeds responsiveness (10). No community is exempt of incidents classified as disasters, and their occurrence may rise through the years. For this reason, efforts like the creation of the world atlas of natural disaster risk, which maps the distribution of specific disaster hazards worldwide, help to improve policies, and local actions (27).

During the year 2013, natural disasters and social conflicts affected about 148.2 million people (8). The United Nations reported on the devastating consequences of unpredictable, unpreventable, and impersonating disasters. Over the last two decades, these events had an economic impact of around 2 $\begin{array}{ll}\text { Rodrigo RAMOS-ZUÑIGA } & \text { (D) : 0000-0001-7643-4129 } \\ \text { José Rodrigo ARELLANO-CONTRERAS } & \text { (1) : 0000-0002-7401-5585 }\end{array}$
Jorge Alejandro ROCHIN-MOZQUEDA (1) : 0000-0002-3736-2326 José Alberto PLASCENCIA-JIMÉNEZ (1) : 0000-0002-8667-9223 
Table I: Etiologic Descriptors

\begin{tabular}{ll}
\hline Man Made Disasters & Natural Disasters \\
\hline Chemical & Earthquakes \\
Biological & Wildfires \\
Nuclear/Radiological & Floods \\
Explosions & Heat waves \\
Ineffectivedam & Hurricanes \\
Civilian disturbances & Avalanche \\
Mechanical & Storms \\
Violence/Terrorism & Tornado \\
& Tsunami \\
\hline
\end{tabular}

trillion United States dollars (USD) and the loss of around 1.3 million human lives (1).

In the morning of September 19, 2017, a 7.1 magnitude earthquake with its epicenter in the state of Morelos stroke Mexico City and four other cities, leaving around 19 million people affected.

Although the response and the initial organization networks and interventions were timely, it exposed, more than ever, the challenges we must solve as a society; and the need of direct interventions of professional/medical associations, in not only the academic or in-hospital context, but also in the on-site scenario. This will allow us to provide immediate medical attention, preventing death by both severe and survivable injuries.

\section{MATERIALS and METHOD}

We conducted a search of information during the following months after the earthquake took place. This included official reports from institutional and government media, and social media such as WhatsApp, Twitter and Facebook, using the key word \#earthquakemexico. This information was filtered and only public health and sanitary data intended to manage the emergency response (both official and civil) was included, ruling out those of personal interest. Once collected, this information was subjected to a qualitative descriptive analysis and then compared to the official information in order to assess the reach and efficacy of the institutional intervention.

\section{RESULTS}

The more used means to communicate general information, regarding guidelines, strategies, advice, and instructions to attend the emergency on a greater scale was Twitter, where the civil population had the initiative to use the key word \#earthquakemexico that was very useful. In comparison, personal emergency communication was conducted mainly via WhatsApp. Official institutions and different government branches like the Mexican Institute of Social Security (IMSS), Civil Protection and other medical institutions had no presence in social media, for there were no instructions, guidelines or organizational strategies for the emergency management to the general public, which led to a disorganized intervention and less reach. Collegiate medical institutions, specifically neurosurgeons, which did not participate actively on their official media or any other social media, ended having an almost inexistent on site direct actions during the emergency.

Late statistics reported 331 deaths, with more than 6,000 people seeking for medical attention around local health institutions, and 391 people admitted to the hospital (54 in critical condition) (24). It also had a major economic impact affecting productive activities in $16.1 \%$ of the productive/ commercial establishments (14).

\section{DISCUSSION}

After an earthquake, the most common types of injuries are limb injury (fractures) and soft tissue defects (laceration), representing around $70 \%$ of all lesions $(7,16)$. With regard to neurosurgical lesions, previous reports from the Van earthquake on 2011 showed that the most common injuries were spinal fractures and spinal cord injuries, scalp injuries like depressed skull fractures, and cerebral hemorrhages. $(3,15)$ (Table II).

There is an increasing need in improving pre-hospital management through well-structured responses and effective communication with hospital staff and specific neurosurgicalmedical teams with the basic skills that the caregiver must have in order to be qualified to confront a disaster, such as quick response, recovery, preparedness and mitigation (19).

\section{The Response to Disaster according to Guidelines}

Back in 2016, The IMSS published an institutional guideline on response to disasters and emergencies (11). It includes certain actions to take into account for preparedness for a mass disaster, in accordance to other international guidelines $(6,22)$. It encloses three crucial phases for event response: the first talks about preparation and organization before a disaster; the second encloses the actions taken during the disaster; and the last provides outlines for the after math of the disaster, in accordance to the levels of intervention (23) (local, state, and federal) (Table III).

\section{Local Response to Disaster}

The central element in effective disaster control encompasses the immediate and structured local responses to the initial toll a disaster may cause through the deployment of local resources and emergency medical management.

State, federal and international support can be involved in handling any disastrous incident, but it is the local response what will dictate the success or failure of the intervention. The medical personnel involved must know all the available resources, the hierarchy in the decision-making and the systematization of civil society processes which is the most relevant immediate action. In México, the Technical Secretary of the National Council for the Prevention of Accidents (STCONARPA), part of the government's Health Secretary, published a manual on 2017 for Civil Protection in the Presence of Emergency, Contingency or Disasters. It states easy-to-follow bullet points of specific recommended actions toward a fast and efficient disaster response; it mainly applies 
Table II: Most Common Body Parts Injured in Some of the Major Earthquakes of the Past Years in the World

\begin{tabular}{|c|c|c|c|c|c|c|c|c|c|}
\hline $\begin{array}{l}\text { Disaster } \\
\text { (Reference) }\end{array}$ & Head & Face & Thorax & Spine & $\begin{array}{c}\text { Upper } \\
\text { Extremities }\end{array}$ & $\begin{array}{c}\text { Lower } \\
\text { Extremities } \\
\text { and Pelvis }\end{array}$ & Abdomen & $\begin{array}{c}\text { Body } \\
\text { Surface } \\
\text { and Others }\end{array}$ & Total \\
\hline & n (\%) & n (\%) & n (\%) & n (\%) & n (\%) & n (\%) & n (\%) & n (\%) & n (\%) \\
\hline China; Apr, 2013 (15) & $73(14.0)$ & $28(5.4)$ & $45(8.6)$ & $52(10.0)$ & $48(9.2)$ & $178(34.2)$ & $4(0.8)$ & $93(17.8)$ & $521(100)$ \\
\hline China; May, 2008 (11) & $204(11.0)$ & & $474(25.5)$ & - & $911(49.1)$ & & - & $267(14.4)$ & $1.856(100)$ \\
\hline $\begin{array}{l}\text { Pakistan; Oct, } 2005 \\
\text { (4) }\end{array}$ & $59(20.0)$ & - & $7(2.0)$ & - & $68(23.0)$ & $114(40.0)$ & - & $43(15.0)$ & $291(100)$ \\
\hline Iran; Dec, 2003 (19) & $180(13.6)$ & $136(10.3)$ & $114(8.6)$ & $156(12.0)$ & 149 (11.3) & $481(36.2)$ & $106(8.0)$ & - & $854(100)$ \\
\hline
\end{tabular}

Table III: Emergency Levels of Disaster

\begin{tabular}{ll} 
Level I & $\begin{array}{l}\text { Local emergency medical services and hospitals } \\
\text { are capable of attending the demands. } \\
\text { One regional hospital active. }\end{array}$ \\
\hline Level II $\quad \begin{array}{l}\text { Two or more regions affected. } \\
\text { Interjurisdictional effort required. } \\
\text { Many active regional hospitals required. }\end{array}$ \\
\hline $\begin{array}{l}\text { State or federal aid required. } \\
\text { Intervention according to the needs. }\end{array}$ \\
$\begin{array}{l}\text { May require international intervention if } \\
\text { overwhelmed. }\end{array}$
\end{tabular}

Table IV: Classification of Patients according to the Severity of the Injury

\begin{tabular}{ll}
\hline Priority 1 (red) & Severe injury. High priority transport. \\
\hline Priority 2 (yellow) & $\begin{array}{l}\text { Moderate injury. Medium priority/ } \\
\text { delayed transport. }\end{array}$ \\
\hline Priority 3 (green) & Mild injury. No transportation needed. \\
\hline Deceased (black) & No intervention. \\
\hline
\end{tabular}

to brigades, rescuers, and first contact personnel. The most important points focus on on-site security measures such as rapid evacuation, assessment of damage, quick mobilization of injured people or even early response with first aid services as needed (18).

On the other hand, it is important to coordinate the response of the community. In face of disaster, there is a grand sense of solidarity with an increase in the number of informal volunteers arriving at the site, sometimes hindering the work of qualified personnel. It is important to coordinate the activities of the convergent volunteers with a systematic approach. Collegiate societies can have an efficient leadership and should offer their services through coordination and organization of the social contribution response.

\section{State level disaster response}

The state function consists of at least the following components: 1) coordination of activities in multiple localities through a State Center of Emergency Operations (SCEO); 2) mobilization of specific state organisms for disaster response; 3) specify mutual aid agreements between several states; 4) access and coordinate the deployment of federal resources (22).

\section{Federal response to disaster}

Without the initial local response, federal aid during disasters cannot effectively mitigate morbidity and mortality. Local providers, with the collegial support of professional societies (paramedics, neurosurgeons), should carry out the initial search and rescue, as well as first aid and pre-hospital and in-hospital care.

However, after the initial local response, health centers in the disaster zone and adjacent locations should expect a rapid and organized federal response.

For a more efficient and safer management of victims of disasters in need of medical attention, a collaborative effort between local providers and leaders is required, using the available infrastructure corresponding to the federal response adequately. This same strategy will determine the activation of disaster intervention plans by other authorities at the time, such as the military forces $(25,29)$.

\section{Hospital and Site Response}

The operational response for a massive casualty involves an establishment of an incident management team structure, with the deployment of health teams and commanders on the site of the emergency. This response is developed according to the surge capacity, which is defined in terms of space, staff supplies, and system. The mass influx of patients may result in a health facility exceeding capacity, so it is important to assess the resources and administer them accordingly (26).

The hospital system flow should center in maintaining access to care for the greatest number and to ensure a safe pass to the next level of attention when required. Also identifying potential and real bottlenecks is important, specifically in terms of transport, operative table selection, and critical care $(26,28)$.

The site health team deployment, as suggested in many guidelines, should have the following structure: a site coordinator and a site health team, and the decision to send site health teams must be based on the resources and 
capacity -so that the main health centers do not diminish their capacity- the size, location, and number of casualties. Also the site teams should be sent to the site of the emergency if a large number of patients will remain in the scene for longer than 30 minutes and require specific care (26).

The pre-hospital management should be in line with the standard guidelines. Establishing a chain of command to keep the site intervention and supporting activities controlled. The main role of the site health team is to determine priorities for care and disposition from the scene, moving patients from forward areas to treatment areas, in other words to take care of the triage of the patients, especially in the context of limited resources, so that the majority of the patients receive the appropriate treatment. An effective triage prioritizes casualties as shown in Table IV.

The focus of the site intervention is to prioritize patient needs and to provide rapid interventions in patients with survivable injuries, to stabilize before transportation and to provide analgesia and advance care when needed. The clearing post focuses on priority 1 and 2 patients (9).

For the patients with neurological injury, they tend to fall in the priority 1 (red) category especially because of severe traumatic skull/brain injury. The aim is to prevent secondary injury and a rapid transportation of those with high probability to survive. Usually these patients require a more integrative intervention on every level of attention during the casualty (28). Also we recommend the presence of a neurosurgeon in the triage system and in first evaluation on site, from local hospitals in the region with CT scan, because this will be a relevant strategy to obtain information to make decisions from a neurosurgical view.

\section{The strategy of response in the digital age: What we have learned from México on 19.09.2017.}

One of the most relevant and positive acts in the social reaction to mass disaster, seen through the multiple events in the past few years, is the immediate response deployed through social media, surpassing even government's initial mass emergency protocols (5). Mexico's earthquake was no exception. Driven by altruism and solidarity, people used social networking to pinpoint important locations such as hospitals, shelters and areas at risk, allowing a faster response in aid and recovery.

Social networks have shaped the interaction of society and health workers showing a great impact in all the phases of the disaster cycle. For instance, the use of Facebook and Twitter during the 2010 Haiti Earthquake was an effective and accessible means of communication and organization (21). In 2014, Facebook implemented a program called "safety security check" that served as a communication link between people affected and helped to know their status in real time. Local civic institutions used these platforms to generate a broader content of social guidelines that helped mitigate the initial toll of the emergency.

In 2012, the American Red Cross assembled a group of digital volunteers that ran what they called a Digital Disaster Operations Center (DigiDOC) that operated for the first time in the events of Hurricane Sandy. Making information about operational activities (such as volunteering aid and small work groups) readily available through social networks enhanced communication between users and organizations for a more structured disaster response (31).

It is in this scenario that collegiate, academic, and scientific societies, such as neurosurgical societies may give use of digital networks to communicate and design specific plans that can be translated in an organized and early intervention and not just wait for the patient to arrive to the operating room to proceed (19).

There are key elements of the organization response during a mass medical emergency included in the guidelines and recommendations of local authorities for each specific crisis $(13,18)$. It includes identification of areas at greater risk, immediate response (providing counseling and support in the primary care), and on-site participation of qualified work teams for patients that require a complex care. More recently, the creation of strong networks of communication in all levels of disaster response that prioritizes social involvement in an organized and systematic manner and facilitates the diffusion of medical data available from professionals appears to be a valuable strategy. Across the area affected, collecting information in a database may ease the decision-making process and would serve as an evaluation tool for actions taken during the emergency after the crisis is over (25). This includes a health information infrastructure and geographical tracking systems like the Virtual Center of operations in emergencies and disasters (CVOED) created by the IMSS (10, 13). Of course, any action must adapt in accordance on the level of emergency, whether it requires local, state or federal intervention.

The latest earthquake in México showed the gaps between theory and practice: at least six thousand people needed some kind of medical attention in the acute phase of the disaster, having 46 available hospitals with approximately 417 total emergency room beds available (14). There was clearly an unbalance between demand and offer capabilities. That revealed the need for a more structured approach that is only possible through clear and easy-to-follow recommendations.

\section{Recommendations for Efficient Disaster Response: The Role of the Neurosurgeon}

There is a crucial need to have well defined action frameworks in which qualified personnel can intervene with both internal and external leadership, to avoid dualities and loss of time and resources. The construction of guidelines should consider the different levels of disasters allowing focusing an effective strategy that does not disrupt normal structure or hospital functionality (6).

Communication during an emergency is imperative; it must be scalable, interoperable and replicable. It should also adhere to the basic ethical codes that confirm the veracity and reliability of the information gathered and broadcasted. It is important to be clear about who is the recipient of the message, and to make sure that the content is clear (11). In the September earthquake in Mexico City, Twitter was the most used social 
network, especially among young people. It had an important social role in assessing real time security hazards (in the context of on-site situations), and as a means to request paramedical support and equipment, facilitating the rescue of people and sending small alerts to keep the roads between the disaster sites and the hospitals clear. On the other hand, WhatsApp was widely used for group communication, though it lacked appropriate verification of the veracity and reliability of the information shared, being mainly useful for inter-group communication (17).

The recent advances in mass communications translate into new opportunities of accessing fast and reliable information for a quicker and more effective response. However, there are limitations to this approach, for instance the risk of infrastructural damage may render these means of communication as inoperable; it may also be quite difficult to reach vulnerable or isolated communities with this method. For this reason, it is important to have alternatives and to diversify our means of communication for such cases $(11,29,30)$.

It is important to establish the organization chart and the mechanisms and principles to attend the emergency systematically; taking advantage of social media and other networks (such as corporate internal networks) (30). In a cohesive and focused work group, members must immediately report their location and availability in the case of emergency. After that, they must define their level of engagement, either at the emergency site, enrolling in the direct identification of problems and early management of health-associated problems, including triage, classification of patients, and immediate pre-hospital care; or in the hospital of their affiliation preparing the human team, supplies, and operating rooms for the reception, and intervention of patients (2).

From a neurosurgical perspective, the personnel included in this strategic program must have their Advance Trauma and Life Support (ATLS) skills, critical care skills and vertical training in both neurosurgical and general trauma management guidelines in order to provide immediate management in the pre-hospital and hospital setting. Therefore, the role of the neurosurgeon in a mass emergency is mainly to identify salvageable from non-salvageable casualties and focus on the first ones (2).

Usually the majority of patients arrive to the appropriate medical service in around 90 minutes, where they will receive the definitive management. It is important to note that the first patients to arrive at the hospital are those with mild lesions, because the ones with severe lesions usually require a more specialized on-site intervention. In this case, the neurosurgeon must be able to administer both diagnostic and interventional resources so that they can be easily accessible to those who will need them the most (2).

Ideally, the response time should be shorter in order to achieve better outcomes. For this purpose, a database listing the personnel with their experience card, their location, and accessibility to pre-hospital paramedical support networks as well as their link with hospitals with neurosurgical service should be available $(2,30)$.

\section{CONCLUSION}

The participation of social leaders and qualified personnel providing support and advice in massive medical emergencies and disasters is feasible if done in an organized manner, and meeting basic criteria of organization, guidelines, and algorithms of management. The integration of an immediate response network in a disaster is a strategy, which allows neurosurgeons and other physicians who have decided to cooperate in these situations to link to this network, through mobile devices and other technologies, and provide qualified advice and aid to professionals and members of the community. This network would potentially allow neurosurgeons and other healthcare providers to participate more actively in the pre-hospital care of the patients affected by the disaster. Their early intervention in the classification, triage, and initial management will result in a more expeditious and efficient medical care and reducing the time taken in the referral of the patient to hospitals with space and capacity to provide the definitive specialized treatment required.

\section{ACKNOWLEDGEMENT}

The authors would like to thank Enago for the English language editing.

\section{- REFERENCES}

1. Andrews RJ, Quintana LM: Unpredictable, unpreventable and impersonal medicine: Global disaster response in the 21st century. EPMA J 6(1):2, 2015

2. Armonda RA: The management of mass casualties. Congress Quarterly 12:15-16, 2011

3. Aycan A, Yener U, Aycan N, Gonullu E, Dursun R, Gonullu H: Neurosurgical injuries caused by the 2011 Van earthquake: Experience at the Van regional training and research hospital. J Emerg Med 49: 464-470, 2015

4. Bai XD, Liu XH: Retrospective analysis: The earthquakeinjured patients in Barakott of Pakistan. Chin J Traumatol 12:122-124, 2009

5. Callcut R, Moore S, Wakam G, Hubbard AE, Cohen MJ: Finding the signal in the noise: Could social media be utilized for early hospital notification of multiple casualty events? Plos One 12:1-12, 2017

6. Centers for Disease Control and Prevention (CDC): Planning for an emergency: Strategies for identifying and engaging atrisk groups. A guidance document for Emergency managers: First edition. Atlanta (GA): CDC, 2015.

7. Clover AJP, Jemec B, Redmond AD: The extent of soft tissue and muskuloskeletal injuries after earthquakes; describing a role for reconstructive surgeons in an emergency response. World J Surg 38: 2543-2550, 2014

8. Cohn JV, Schatz S, Freeman H, Combs DJY: Modeling Sociocultural Influences on Decision Making. Understanding Conflict, Enabling Stability. United States: CRC Press, 2016

9. Gautschi OP, Cadosch D, Rajan G, Zellweger R. Earthquakes and trauma: Review of triage and injury-specific, immediate care. Prehosp Disaster Med (23)2:195-201, 2008 
10. Harrison JP, Harrison RA, Smith M: Role of information technology in disaster medical response. Health Care Manag 27: 307-313, 2008

11. Hossain L, Feng S: Disaster network science: Research and applications. Frontiers in Communication 1(1):1-7,2016

12. Hu Y, Zheng X, Yuan Y, Pu Q, Liu L, Zhao Y: Comparison of injury epidemiology between the Wenchuan and Lushan earthquakes in Sichuan, China. Disaster Med Public Health Prep 8:541-547, 2014

13. Instituto Mexicano del Seguro Social: Guía para que las Unidades elaboren el Plan Frente a Emergencias y Desastres. 2016

14. Instituto Nacional de Estadística y Geografía (2017, september 29) Estadísticas sobre las afectaciones de los sismos de septiembre de 2017 en las actividades económicas from: http://www.inegi.org.mx/saladeprensa/boletines/2017/ afectaciones/afectaciones2017_09.pdf

15. Kalantar Motamedi MH, Sagafinia M, Ebrahimi A, Shams E, Kalantar Motamedi M: Major earthquakes of the past decade (2000-2010): A comparative review of various aspects of management. Trauma Mon 17:219-229, 2012

16. Kang P, Tang B, Liu Y, Liu X, Liu Z, Lv Y, Zhang L: Medical efforts and injury patterns of military hospital patients following the 2013 Lushan earthquake in China: A retrospective study. Int J Environ Res Public Health 12:10723-10738, 2015

17. Kapucu N, Haupt B: Information communication technology use for public safety in the United States. Front Commun 1: $1-9,2016$

18. Manual de Protección Civil ante Casos de Emergencia, Contingencias y Desastres del STCONAPRA. Secretaría de Salud/STCONAPRA. México, Ciudad de México, 2017

19. Mew E, Foong Chong S, Barker W, Houston J: Disaster medicine. London:Springer, 2013

20. Mohebbi HA, Mehrvarz S, Saghafinia M, Rezaei Y, Kashani SM, Naeeni SM, Motamedi MH, Hoseini SH, Moharamzad Y: Earthquake related injuries: Assessment of 854 victims of the 2003 Bam disaster transported to tertiary referral hospitals. Prehosp Disaster Med 23:510-515, 2013
21. Muralidharan S, Rasmussen L, Patterson D, Shin JH: Hope for Haiti: An analysis of Facebook and Twitter usage during the earthquake relief efforts. Public Relations Review 37:175177,2011

22. National Disaster Management Authority, Government of India: National Disaster Management Plan (NDMP). New Delhi, Government of India, 2016

23. Office of Disaster Preparedness and Management. National Response Framework, levels 1 to 3 [Office of Disaster Preparedness and Management website] 2013. Available at: http://www.odpm.gov.tt/node/66. Accessed May 1, 2018

24. Pan American Health Organization/World Health Organization. Sismo México-Análisis de situación. 25 Septiembre 2017. Washington, DC: PAHO/WHO, 2017

25. Partridge RA, Lorens P, Marcozzi D: Oxford American Handbook of Disaster Medicine. New York: Oxford University Press, 2012

26. Queensland Health, State of Queensland. Queensland Health Mass Casualty Incident Plan (QHMCI-PLAN). Queensland, USA, 2016

27. Shi P, Kasperson R: World Atlas of Natural disaster Risk. Beijing: Springer, 2015

28. Talati S, Bhatia P, Kumar A, Gupta AK, Ojha CD: Strategic planning and designing of a hospital disaster manual in a tertiary care, teaching, research and referral institute in India. World J Emerg Med (5)1:35-41, 2018

29. Tuckson VT, Dzau VJ, Lurie N: Creating healthy communities after disasters. N Engl J Med 377:1806-1808, 2017

30. Velev D, Zlateva P: Use of Social Media in Natural Disaster Management. Paper presented at ICITE 2012: at Hong Kong. Volume: IPEDR, vol: 39, 2012

31. Yan L, Pedraza-Martinez A: Social media for disaster management: A study of hurricane sandy. Kelley School of Business Research Paper 7:16-11, 2017 